\title{
AN EIA FOR EVERYONE? ANALYZING THE LOW-INCOME INCLUSIVITY OF ENVIRONMENT IMPACT ASSESSMENTS IN INDIA
}

\author{
Aryamaan Singh \\ delhi public school vasant kunj, new delhi \\ DOI: 10.46609/IJSSER.2020.v05i12.015 URL: https://doi.org/10.46609/IJSSER.2020.v05i12.015
}

\begin{abstract}
The process of the Environmental Impact Assessment (EIA) in India is riddled with loopholes which have left the environment and low-income communities susceptible to increasing levels of corporate exploitation. Such adverse consequences primarily stem from the purely economic and development-oriented approach, rather than a holistic approach to the EIA process. This paper will examine the flaws with such an approach and examine the dire need for inclusivity and participation from low income, marginalized communities, particularly indigenous populations who depend on natural resources for their income and survival. With the threat of global warming and rising sea levels, it is necessary to reform the EIA process and make it more democratic and inclusive, rather than dilute provisions for public participation. This paper will propose policy measures and a roadmap for a more equitable approach to EIA and the importance of such inclusivity to local communities and the environment itself.
\end{abstract}

Keywords: EIA, Income, Population, Environment, Sea Level

\section{Introduction}

Under the current Indian legal framework, the Environmental Impact Assessment established under the Environment (Protection) Act, 1986, or EIA is the process or study which predicts the effect of a proposed industrial/infrastructural project on the environment. It prevents the proposed activity/project from being approved without proper oversight or taking adverse consequences into account (The Hindu, 2020). The structure of the existing EIA regulations in India is that it is a scientific estimate of the likely impacts of a project, such as a mine, irrigation dam, industrial unit or waste treatment plant. It is a process whereby people's views are taken into consideration for granting final approval to any developmental project or activity (The Week, 2020). Therefore, the process of conducting an EIA and the ultimate result have far reaching politico-economic and societal consequences, as it affects industrialization, employment in the area, biodiversity, and pollution, among several other related factors. With 


\section{International Journal of Social Science and Economic Research}

ISSN: $2455-8834$

Volume:05, Issue:12 "December 2020"

the looming threat of climate change, there has been an increase in activism and focus on democratizing the process of conducting an EIA.

This paper will provide a brief history of EIA regulations in India, and trace the development and critiques of the same until the recent changes implemented in 2020. The paper will examine the dire need to conceptualize the EIA process beyond economic metrics, but rather from a sociological perspective that includes low income communities and those communities which thrive on the biodiversity and depend on it for survival. The paper will evaluate case studies to highlight the importance of such inclusion and propose policy measures to strengthen and democratise EIA norms in a more holistic and interdisciplinary fashion.

\section{Background}

Under the Environment (Protection) Act, 1986, India notified its first EIA norms in 1994, setting in place a legal framework for regulating activities that access, utilise, and affect (pollute) natural resources. Every development project has been required to go through the EIA process for obtaining prior environmental clearance ever since (Mazoomdar, 2020). The 1994 EIA notification was replaced with a modified draft in 2006. Earlier this year, the government redrafted it again to incorporate the amendments and relevant court orders issued since 2006, and to make the EIA "process more transparent and expedient" (Mazoomdar, 2020). The environment impact assessment consists of eight steps with each step equally important in determining the overall performance of the project. Typically, the EIA process begins with screening to ensure time and resources are directed at the proposals that matter environmentally and ends with some form of follow up on the implementation of the decisions and actions taken as a result of an EIA report (CSE, n.d).

In recent years there has been a greater interest in developing the theory underpinning EIA, which began as a very practical tool to aid decision-making. Since its origins in the 1960s EIA has had to adapt to different contexts, most notably the concept of sustainable development which came to prominence after EIA had already started being used. Today, we tend to see EIA as one of the suite of tools that help support more sustainable decision-making, but there is a wide range of views as to how effective it can be from a theoretical point of view (SOAS, n.d). Different schools of thought place importance on different aspects of the EIA, for example the rationalist model focusing on EIA as a tool for development, ecotheology which views it was a step towards the protection of the Earth and ecofeminism is focused not only on the output of the EIA process, but rather, the process itself and the importance engaging with stakeholders that EIA engenders and the potential for dialogue created which may have greater value (SOAS, n.d). 


\section{International Journal of Social Science and Economic Research}

ISSN: $2455-8834$

Volume:05, Issue:12 "December 2020"

Re-evaluating the manner in which the EIA process is implemented in India is crucial given the vulnerability of the environment to corporate exploitation, loss of biodiversity, and forest degradation. In India, average temperatures have increased by about 0.8 degrees Celsius (0C) since 1901. But the rate of warming has speeded up since 1981, and our average temperature is rising by $0.170 \mathrm{C}$ per decade (Adve, 2020). This has led to rising sea levels, adverse impacts on coastal communities, droughts in many places, migration and extinction of species, etc (Adve, 2020). There has been large criticism of the Draft EIA norms introduced by the Indian government in 2020, which is seen by activists as only exacerbating these issues. Among the most damaging provisions are the dilution of punishment for violators and removal of public hearings, the exemption of several classes of industries from public consultation, among others (Rao, 2020). The new EIA norms also allow for post-facto approval for projects. It means that the clearances for projects can be awarded even if they have started construction or have been running phase without securing environmental clearances (The Week, 2020). This also means that any environmental damage caused by the project is likely to be waived off as the violations get legitimised (The Week, 2020). These issues create loopholes in the EIA process that is skewed towards corporate exploitation of natural resources even further. Therefore, the following section of the paper will discuss the implications and drawbacks of the purely development oriented approach to the EIA, and ways forward to increase inclusivity and protect biodiversity.

\section{Discussion}

There is an increasing social and sociological importance of considering EIAs beyond purely economic standpoints and approaching the same only as a means to an end for economic growth. To this end, there is a dire need for effective inclusion of the needs and concerns of low-income communities, including lower caste communities as well as gender minorities within norms of the EIA, as vulnerable groups. The draft EIA grossly neglects consultation with the affected communities. To limit public consultation means to silence voices that are barely heard otherwise (Mohanty, 2020). The new draft will strengthen discretionary power of government while restraining public engagement in safeguarding the environment. The time allotted for public hearings has been reduced to expedite the process of several projects which have been approved without concern for the impact on the environment. Public participation has been crucial in the EIA process and has significantly helped communities to not only get information about the projects being proposed in their areas, but also to speak about their concerns regarding the projects (Mohanty, 2020). However, the rights of communities have been weakened by legalising projects that have already caused a great deal of harm and have been operating without approvals from the EIA (Mohanty, 2020). 


\section{International Journal of Social Science and Economic Research}

ISSN: $2455-8834$

Volume:05, Issue:12 "December 2020"

The current role of EIA in India in particular, and developing countries in general, can be said to follow the model in which the elite few (politicians and industries in this case), set the agenda and use the EIA process to justify decisions already made by them, with limited one-way consultation after the EIA studies are completed (Rajaram and Das, 2007). Various studies have shown a positive correlation between poverty alleviation and the conservation of natural resources. Methods to empower poor people to articulate their rights and linkages with their ecosystems will enable them to better defend and demand compensation when threatened with degradation and/or displacement (Rajaram and Das, 2007). Local ecological knowledge should be given a primary role to understand the full range of socio-ecological linkages and thereby impacts of any activity. Efforts in the coming years should be directed to enhance the socioecological linkage document through use of tools like remote sensing to enhance its accessibility to all stakeholders in environmental management (Rajaram and Das, 2007). The challenges in this endeavor would be to create elements at the village level capable of framing adaptive management strategies to maintain resource extraction rooted in frugality and equity and begin the journey towards sustainability (Rajaram and Das, 2007).

To this end, methods of incorporating the needs of indigenous communities in India must be implemented, which is lacking. For example, the 2011 government scheme National Innovations in Climate Resilient Agriculture (NICRA) identified 151 climate-vulnerable villages across states for a range of interventions, depending on the climate stresses. These include moisture conservation techniques such as mulching, construction of farm ponds, introducing shortduration crop varieties, drought-tolerant varieties, etc (Adve, 2020). However, a recent analysis finds it is hampered by low participation in selected villages, understaffing, and poor integration with other existing programmes (Adve, 2020).

All over India, struggles have intensified against displacement and for local community control over commons resources like forests, agricultural land, wetlands, rivers, and the sea. These are being waged against mining projects, coal power plants, aluminium projects, nuclear plants, against land being taken for 18 vast industrial belts, such as the Delhi-Mumbai Industrial Corridor, and most recently, against the Mumbai-Ahmedabad bullet train (Adve, 2020). The involvement of indigenous communities in Orissa led to the consent of Gram Sabhas being established as a statutory right in the Niyamgiri Mining Case, wherein the Supreme Court had, in an order delivered in April 2013, directed Odisha Mining Corporation to obtain 'consent' of 12 Gram Sabhas - seven in the Rayagada district and five in the Kalahandi district - before proceeding with bauxite mining in the region (Das, 2020). However, the positive impact or involvement of indigenous communities has remained few and far between in the face of development and economic oriented approaches to the EIA and the lack of inclusivity codified in formal provisions of law. 


\section{International Journal of Social Science and Economic Research}

ISSN: $2455-8834$

Volume:05, Issue:12 "December 2020"

\section{Conclusion}

There are a large number of communities like Adivasis, peasants and coastal and fisher communities whose lives mainly depend on the state of the environment. Any drastic changes in EIA will have a direct impact on the living and working conditions of these people and the ecology (Mohanty, 2020). Participatory mechanisms are crucial to the survival of these indigenous communities. Such mechanisms will hold great importance in bridging social, economic, and political concerns alongside environmental concerns and not targeting each in an isolated fashion. However, the process of EIA however has been reduced to a mere technical process with very little importance given to socio-economic issues, including those related to gender (CSE, 2018). On the contrary, it can be demonstrated how adverse impacts of development projects can be reduced with the full and equal participation of both genders, particularly women, because of their decision-making capacities, organic knowledge of local topography and ecosystems, and concern regarding drinking water, sanitation and health (CSE, 2018). It is important to avoid the damaging of traditional ecosystems and occupations, local economics and pollution of agriculture and water bodies. The fact that the poor are without the means such as education, capital, land, etc. to participate in the liberalized economy is yet to be acknowledged by governmental policy (Das and Rajaram, 2007).

It is crucial to prevent violations such as Vedanta violating legal provisions to accrue benefits at the cost of the local tribal community, and similar breaches at a Reliance power plant in Madhya Pradesh, and an Essar Power plant which had resulted in 500 farmers losing their crops (Adhya, 2020). A similar incident was reported on May 27 2020, where due to poor adherence of environment norms, the natural gas of Oil India Limited in eastern Assam's Tinsukia district had a blowout and caught fire. This caused severe damage to the livelihoods in the region rich with biodiversity (Mohanty, 2020). India must follow the example of other governments in this regard. For example, pressured by indigenous peoples who form over half its population, the Bolivian government passed the Law of the Rights of Mother Earth in 2010. It recognised that all living things have rights, including the right to biodiversity without genetic manipulation, the right to water to sustain life, and the right to restoration of ecosystems damaged by human activity (Adve, 2020).

The inclusion of low income, marginalized, and indigenous communities in the EIA process is crucial to the protection of biodiversity. The draft EIA notification clearly misses the social aspect of development and exposes the fundamental flaws of a purely economic approach to the EIA process, in its lack of protection or consultation from indigenous and tribal communities (Das, 2020). 
International Journal of Social Science and Economic Research

ISSN: 2455-8834

Volume:05, Issue:12 "December 2020"

\section{References}

Adhya, T. (August 11 2020), 'The Govt is Trying to Make it Easier for Industries to Avoid Environmental Accountability', The Wire, https://thewire.in/government/environment-impactassessment

Adve, N. (2020), 'Global Warming in the Indian Context: An Introductory Overview'

Center for Science and Environment, (August 6 2018), 'Inclusion of Gender in Environmental Impact Assessment', https://www.cseindia.org/inclusion-of-gender-in-environmental-impactassessment-8921

Center for Science and Environment, (n.d), 'Understanding EIA', https://www.cseindia.org/understanding-eia-383

Das, A. (August 12 2020), 'How Draft EIA Notification Compromises Rights of Tribal and Forest Dwelling Communities', Newsclick, https://www.newsclick.in/Draft-EIA-NotificationCompromises-Rights-Trbals-Forest-Dwelling-Communities-Environment-Ministry-PrakashJavadekar-Climate-Change

Mohanty, A. (July 6 2020), 'Why draft EIA 2020 needs a revaluation', Down to Earth, https://www.downtoearth.org.in/blog/environment/why-draft-eia-2020-needs-a-revaluation$\underline{72148}$

Rajaram, T.; Das, Ashutosh (2007). Sustainable frugality through EIA: role of socio-ecological linkages in poverty alleviation. Management of Environmental Quality: An International Journal, 18(5), 556-567. doi:10.1108/14777830710778319

Rao, KM, (10 August 2020), 'Environmental Impact Assessment: Why the govt needs to re-think its latest draft', Down to Earth, https://www.downtoearth.org.in/blog/environment/environmental-impact-assessment-why-thegovt-needs-to-re-think-its-latest-draft-72724

SOAS, (n.d), 'EIA theory and decision-making', https://www.soas.ac.uk/cedepdemos/000_P507_EA_K3736-Demo/unit1/page_11.htm

The Hindu, (July 17 2020), 'What is EIA and why is India's new EIA draft problematic?', https://www.thehindu.com/sci-tech/energy-and-environment/what-is-eia-and-why-is-indias-neweia-draft-problematic/article32110013.ece 
International Journal of Social Science and Economic Research

ISSN: 2455-8834

Volume:05, Issue:12 "December 2020"

The Week, (August 10 2020), 'Explained: What is EIA 2020? How does it water down the existing policy?', https://www.theweek.in/news/biz-tech/2020/08/10/explained-what-is-eia2020-how-does-it-water-down-the-existing-policy.html 